\title{
Chromosome stickiness impairs meiosis and influences reproductive success in Panicum maximum (Poaceae) hybrid plants
}

\author{
C. Pessim ${ }^{1}$, M.S. Pagliarini ${ }^{1}$, N. Silva ${ }^{1}$ and L. Jank ${ }^{2}$ \\ ${ }^{1}$ Departamento de Biotecnologia, Genética e Biologia Celular, \\ Universidade Estadual de Maringá, Maringá, PR, Brasil \\ ${ }^{2}$ Embrapa Gado de Corte, Campo Grande, MS, Brasil \\ Corresponding author: M.S. Pagliarini \\ E-mail: mspagliarini@uem.br
}

Genet. Mol. Res. 14 (2): 4195-4202 (2015)

Received August 8, 2014

Accepted December 11, 2014

Published April 28, 2015

DOI http://dx.doi.org/10.4238/2015.April.28.2

\begin{abstract}
Chromosome stickiness has been studied in several species of higher plants and is characterized by sticky clumps of chromatin resulting in sterility. Chromosome stickiness was recorded in Panicum maximum hybrid plants that were cultivated in the field. In the meiocytes affected, chromosomes clumped into amorphous masses that did not orient themselves on the equatorial plate, and anaphase I disjunction failed to occur. After a normal cytokinesis, the masses of chromatin were divided between both daughter cells. Metaphase and anaphase of the second division also did not occur, and after the second cytokinesis, polyads were formed. This abnormality arose spontaneously. Abnormalities that cause male sterility are an important tool for obtaining hybrid seeds in plant breeding. This is the first report of an abnormality affecting pollen viability in P. maximum. This finding can open a new opportunity in the breeding program of this species that is devoted to hybridization where manual cross-pollination is difficult and time consuming.
\end{abstract}

Key words: Poaceae; Guineagrass; Meiosis; Chromosome stickiness; Hybrid; Breeding 


\section{INTRODUCTION}

The genus Panicum is a large and perennial genus that encompasses annual and perennial forms, and it includes some economically important species such as $P$. maximum Jacq., which is widely known as guineagrass. P. maximum Jacq. is native of Africa, particularly East Africa, Kenya, and Tanzania, where wide genetic diversity is found (Jain et al., 2003).

P. maximum Jacq. is one of the most important forage grass species that is cultivated in Brazil, where it is known as Capim Colonião. Worldwide experience in breeding tropical forage grass is limited. A breeding program is underway at Embrapa Beef Cattle (Campo Grande, Mato Grosso do Sul). The majority of forage cultivars actually in use resulted from the evaluation and selection of natural ecotypes (Jank et al., 2008). Effective breeding programs for $P$. maximum, which is a predominant apomictic tetraploid species (Savidan et al., 1989), must involve intraspecific hybridization, aiming to exploit the genetic variability. Hybridization in guineagrass is possible because of the occurrence of sexual and apomictic plants with the same ploidy level. Taking into account that polyploid species generally display a great amount of meiotic abnormalities that compromises pollen viability (Singh, 1993), this research aims to evaluate the meiotic process in hybrids and their progenitors to investigate the meiotic stability as an additional parameter to select the most interesting hybrid in relation to seed production to address the commercial seed demand.

Meiosis is a highly coherent and genetically programmed process. Like any other biological process, all the sequential steps that are involved in meiosis are controlled by a large array of genes (Baker et al., 1976; Golubovskaya, 1979; Albertsen and Phillips, 1981; Kaul and Murthy, 1985; Caryl et al., 2003; Sosnikhina et al., 2005). Mutations in any of these genes that govern micro- or megasporogenesis from pre-meiotic to post-meiotic events can lead to serious anomalies in the whole process, resulting in genetically aberrant end products that have an adverse impact on fertility and the overall reproductive efficiency of the species. Some mutant genes alter chromosome form and function; others modify integrity, degree of condensation, movement, and migration toward the poles (Kaul and Murthy, 1985). Among the genes that affect microsporogenesis and cause changes in the structural organization of chromosomes, Singh (1993) cited the sticky (st) gene. Chromosome stickiness has been the subject of cytological studies in several species. This investigation deals with the consequences of chromosome stickiness in relation to meiotic behavior and reproductive success in $P$. maximum hybrid plants.

\section{MATERIAL AND METHODS}

\section{Plant material}

The material under analysis consisted of progenitors (P. maximum, line $\mathrm{S} 12$ as female and cv. Tanzania as male), and 12 single hybrid plants. The line S12 is a sexual hybrid plant that was selected in Brazil from a sexual population received from the Institute de Recherche pour le Développment (IRD). The population was derived from a cross between an artificially doubled tetraploid sexual plant and an apomictic accession. The artificially doubled tetraploid sexual plant was obtained from the duplication of the chromosome numbers by colchicine of 
a diploid sexual plant collected in East Africa in 1967. P. maximum cv. Tanzania is a widely used cultivar in the Brazilian pastures, covering around five million hectares. This cultivar was selected by Embrapa Gado de Corte from the IRD collection, and it was commercially released in 1990. The cross between S12 and cv. Tanzania was performed in the field by planting the $\mathrm{S} 12$ in a $25 \mathrm{~m}^{2}$ area of $\mathrm{cv}$. Tanzania. Two cloned plants of S12 were used. These plants were wind-pollinated by the surrounding cv. Tanzania, and seeds were harvested in June 2007 on S12 once they were ripe. Seeds were germinated in the greenhouse in December 2007 and planted in the field as single plants in November 2008 with 1-meter spacing between plants. The site characteristics of cultivation at Embrapa Gado de Corte are: climate type Aw, tropical humid savanna; average annual precipitation, $1526 \mathrm{~mm}$; average temperature, $22^{\circ} \mathrm{C}$; altitude, $520 \mathrm{~m}$; latitude, $20^{\circ} 28^{\prime} \mathrm{S}$; longitude, $55^{\circ} 40^{\prime} \mathrm{W}$; poor dark red latosol soil composed of $29 \%$ sand, $13 \%$ silt, and $58 \%$ clay; $\mathrm{pH}, 5.1$ ).

\section{Cytological analyses}

Inflorescences for meiotic studies were collected from individual plants growing in the field; fixed in 95\% ethanol, chloroform, and propionic acid $(6: 3: 2, \mathrm{v} / \mathrm{v} / \mathrm{v})$ for $24 \mathrm{~h}$; and stored at $4^{\circ} \mathrm{C}$. Anthers containing microsporocytes were isolated from the flowers, and slides containing cell spreads were obtained after squashing and staining with $0.5 \%$ propionic carmine. The number of pollen mother cells (PMCs) analyzed from hybrids ranged from 1360 to 2054. Images were obtained using Kodak Imagelink-HQ, ISO 25 black and white film.

\section{RESULTS}

Anther and pollen development were evaluated in both fertile genitors and in the affected hybrids plants. In the genitors, panicle development was normal in size and number of flowers (Figure 1a). However, in the hybrid plants, the first expression of abnormality was observed in the aspect of panicles. Although the panicles had a normal length, only a few flowers in the racemes showed normal development (Figure 1b). In general, in the hybrids, flowers developed were found only in the apex of the panicle. In fertile racemes of the genitors, all of the flowers were well developed (Figure 2a), whereas a few (Figure 2b) or no flowers (Figure $2 \mathrm{c}$ ) occurred in the hybrids. Compared to the normal fertile plants of both genitors, the affected hybrid plants had smaller, shrunken, and non-dehiscent anthers. In the majority of flowers from hybrids, meiocytes were difficult to find in the anthers because the abnormality impaired the meiotic division. In some anthers, it was impossible to identify the sporogenous tissue. The large number of cells that were analyzed came from a large number of flowers.

Careful analysis of meiosis showed a quite normal meiosis in the genitors; only a few abnormalities related to irregular chromosome segregation were recorded in both (Table 1). In the hybrids, a great number of meiocytes presented abnormal behavior beginning at prophase I, with chromosomes clumping in several groups (Figure 3a-e). Pachytene, diplotene, and diakinesis chromosomes did not present normal configurations. Condensed, sticky chromosomes were dispersed in the cytoplasm or clumped into amorphous masses. Anaphase I and telophase I were not observed. These amorphous masses of chromatin were separated by the occurrence of the first cytokinesis (Figure 3f-h). After this stage, the amorphous masses of chromatin gave 
rise to several micronuclei of different sizes (Figure 3h). Metaphase II and anaphase II also did not occur. Following this phase, the second cytokinesis took place and polyads with microspores of different sizes were formed (Figure 3i). The percentage of meiocytes that was affected by chromosome stickiness ranged from 16.0 to $52.3 \%$ among hybrid plants.

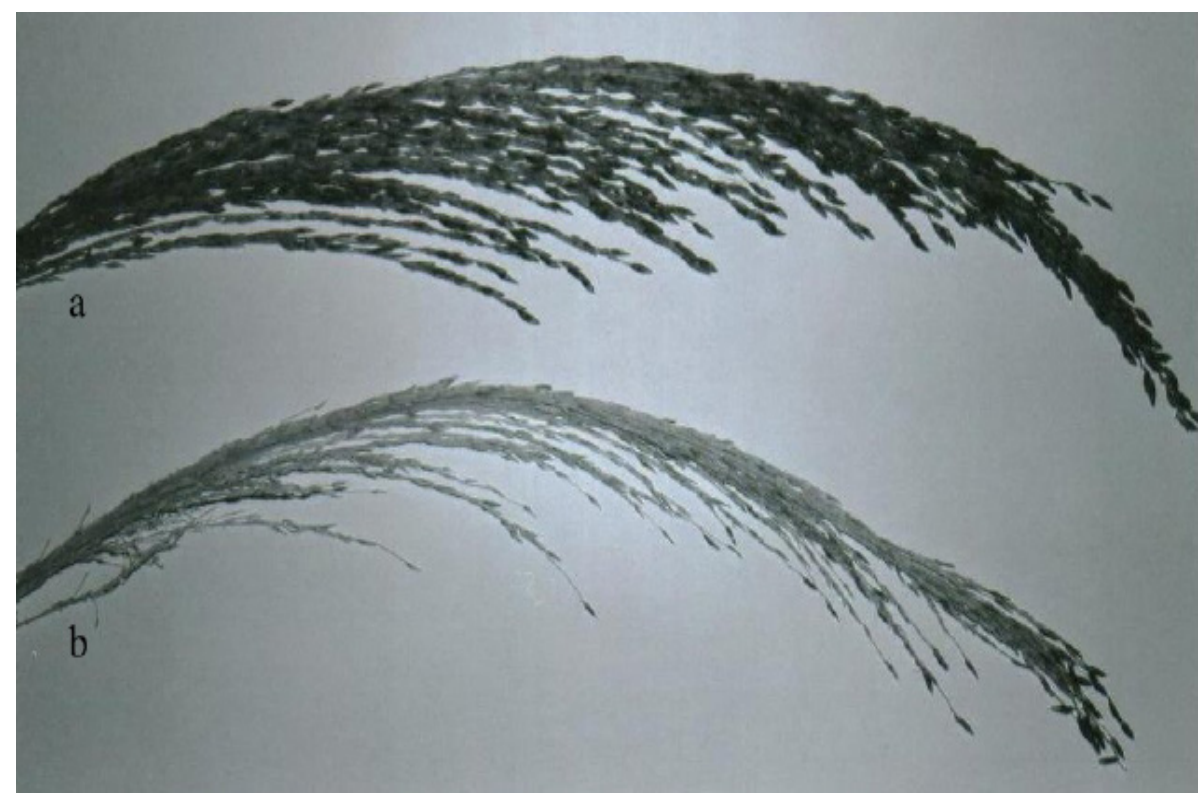

Figure 1. Aspects of panicles in the genitors and hybrid plants. a. All of the flowers in the racemes are well developed in the genitors. b. In the hybrid plants, the flowers are abortive, and only the flowers of the apex show normal development.

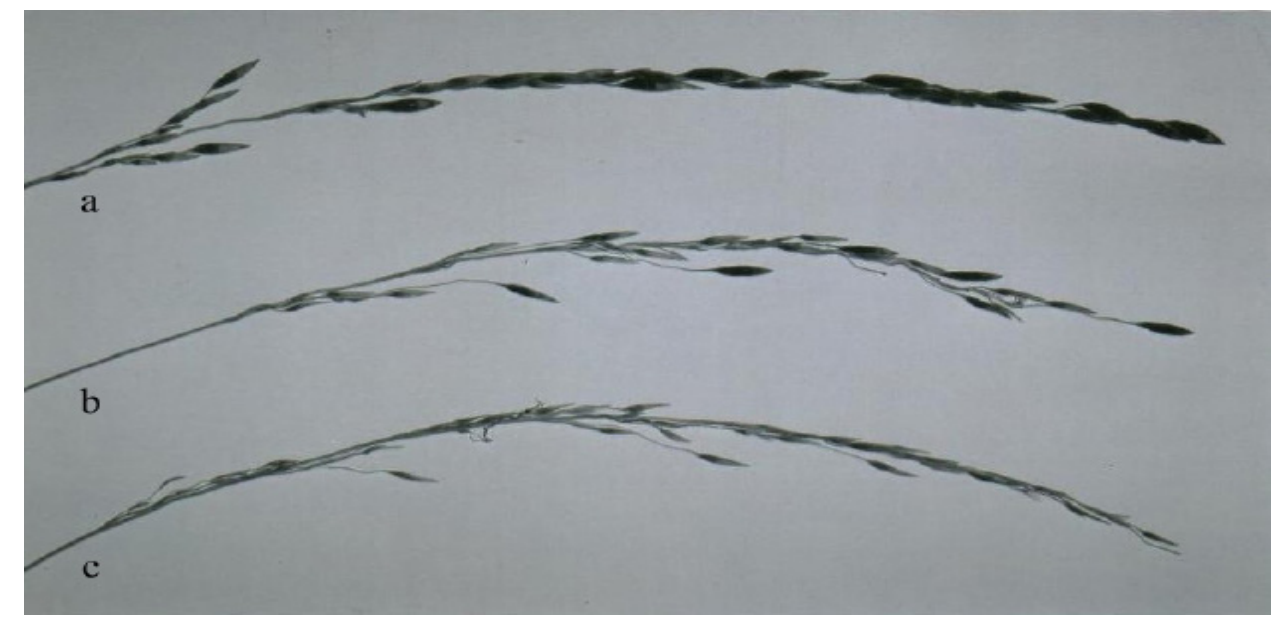

Figure 2. Aspects of racemes in the genitors and in hybrid plants. a. Fertile raceme of the genitors: all flowers are well developed. b. c. Raceme of the hybrids: only a few (a) or none (c) of the flowers are well developed. 
Table 1. Number of cells analyzed and percentage of abnormal cells affected by chromosome stickiness during microsporogenesis in the genitors and hybrid plants.

\begin{tabular}{lcc}
\hline Genotypes & No. of cells analyzed & Percentage of abnormal cells \\
\hline Genitors & & \\
S12 (female) & 470 & $4.9 \%$ \\
cv. Tanzania (male) & 493 & $4.8 \%$ \\
Hybrids & 1482 & $16.0 \%$ \\
E5 & 1970 & $43.2 \%$ \\
E9 & 2054 & $47.0 \%$ \\
E13 & 1672 & $52.3 \%$ \\
E18 & 1746 & $21.4 \%$ \\
E20 & 1662 & $29.6 \%$ \\
E23 & 1360 & $43.4 \%$ \\
D4 & 1719 & $42.0 \%$ \\
D5 & 1471 & $33.0 \%$ \\
D9 & 1531 & $38.4 \%$ \\
D21 & 1517 & $22.4 \%$ \\
DE1 & 1518 & $23.0 \%$ \\
DE2 & & \\
\hline
\end{tabular}

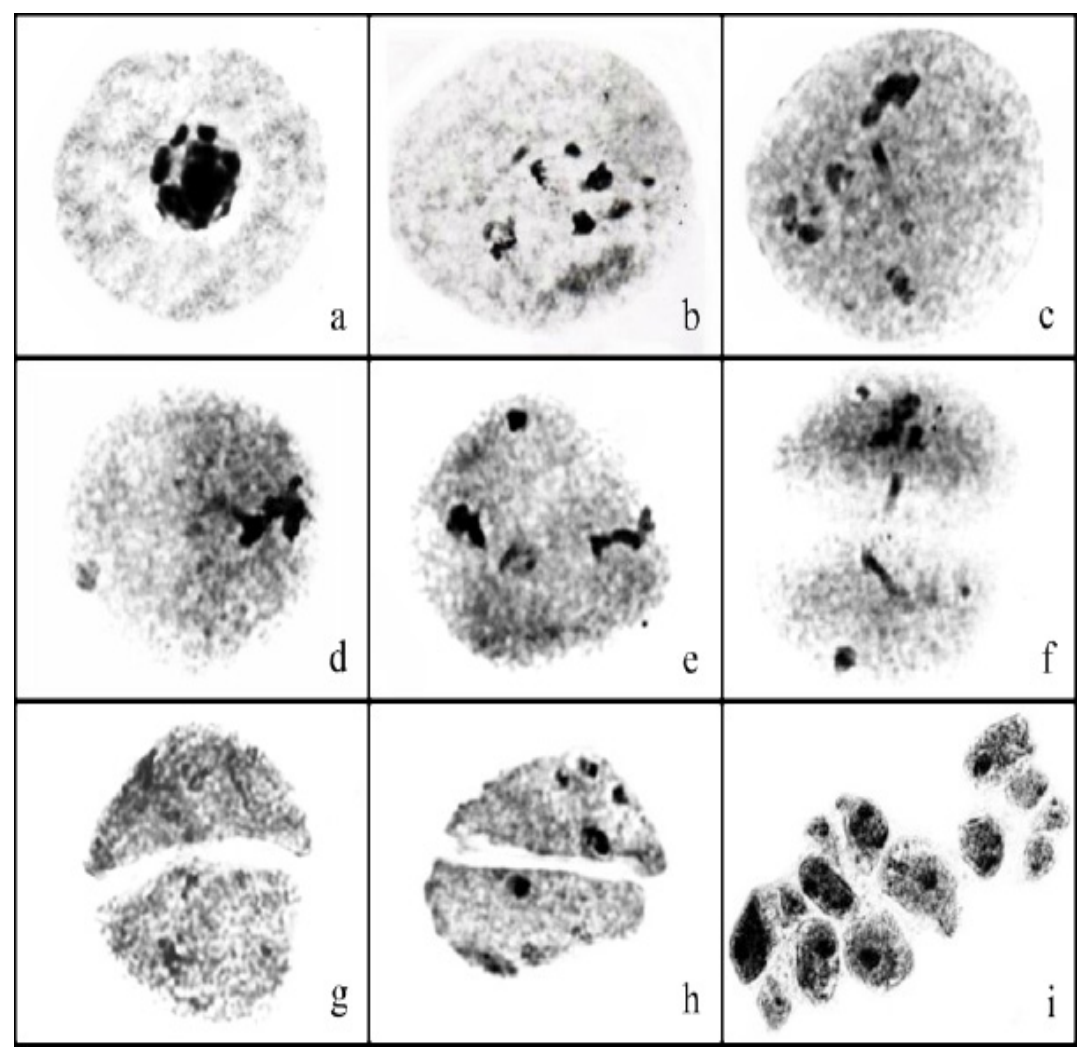

Figure 3. Aspects of microsporogenesis in the hybrid plants affected. a-e. Meiocytes in the first meiotic division showing chromosome stickiness. f-g. Meiocytes in the second meiotic division. h. Telophase II with several micronuclei of different sizes. i. Polyads with microspores of different sizes. 


\section{DISCUSSION}

The genitors presented a quite normal meiosis with less than 5\% abnormal meiocytes. A low frequency of irregular chromosome segregation was also recorded in the genitors of hybrids that were analyzed by Pessim et al. (2010). In the hybrids, the general pattern of chromosome stickiness was similar to that observed in other species (Koernicke, 1905; Carapetian and Rupert, 1977; Sosnikhina et al., 2003). In the cells affected, the chromosomes began to assemble at prophase I or metaphase I, forming sticky clumps that did not orient themselves on the equatorial plate; the anaphase I disjunction was irregular or frequently failed, and chromosome fragmentation occurred from prophase I onward, resulting in sterility. In P. maximum, chromosomes were clumped beginning in prophase I, forming groups inside the meiocyte that failed to orient in metaphases and segregate in anaphases.

Chromosome stickiness was identified earlier by Koernicke (1905) as an effect of ionizing radiation. Stickiness has been the subject of numerous cytological studies; so far, the molecular basis of this type of aberration remains largely unknown (Klásterská et al., 1976; Al Achkar et al., 1989; Tatum and Rayburn, 2006). Gaulden (1987) hypothesized that chromosome stickiness results from changes in specific non-histone proteins (topoisomerase II and peripheral proteins) that are integral components of the chromosome and whose function is necessary for the separation and segregation of chromatids. The changes are caused either by mutation in structural genes for the proteins (heritable stickiness) or by direct action of mutagens on the proteins (induced stickiness). According to this author, chromosome stickiness occurs at various degrees (slight, moderate, severe, and extreme). A factor that would undoubtedly contribute to variability in the degree of stickiness is the number of target protein molecules affected. In our hybrids, the chromosome stickiness could be classified as severe because many or most of the chromosomes were clumped.

According to Gaulden (1987), chromosome stickiness causes chromosome aberrations by the physical stretching and breaking of chromatids at the sticky sites. Among the chromosome aberrations, Dowd et al. (1986) and Gaulden (1987) reported the occurrence of bridges and fragments. In P. maximum, fragments were commonly found in the meiocytes, but bridges were not observed because anaphase failed to occur.

Clear cases of genetically controlled meiotic chromosome stickiness are few. Chromosome stickiness was controlled by a single recessive gene in maize (Beadle, 1933; Golubovskaya, 1979), Triticum durum (Martini and Bozzini, 1965), Collinsia tinctoria (Mehra and Rai, 1970), and pearl millet (Rao et al., 1990b). Duplicate recessive genes in Alopecurus myosuroides (Johnsson, 1944), and two or three recessive interacting genes in Carthamus tinctorius (Carapetian and Rupert, 1977) were also reported. In P. maximum, the genetic nature of chromosome stickiness was not yet elucidated. Spontaneous mutations for chromosome stickiness were independently obtained in rye populations (Sosnikhina et al., 2003). The abnormality that we recorded in the present $P$. maximum hybrid was also spontaneous in nature and emerged among several experimental single hybrids that were growing in the same field.

Abnormalities that cause male sterility are an important tool in the investigation of anther and pollen development and to obtain hybrid seeds in plant breeding (Rao et al., 1990a; Horner and Palmer, 1995; Shifriss, 1997; Atanassova, 2000). The recovery and analysis of new sources of male sterility is one of the most important problems of plant genetics because its solution benefits both plant breeding and studies on sexual reproduction and the interaction 
of different genetic systems of a plant cell (Tsvetova and Elkonin, 2003). In P. maximum, cytogenetic studies on meiosis are rare, and male sterility was not yet reported. More studies are necessary to confirm if this abnormality has a genetic origin. If so, this finding can open new opportunities in the breeding program devoted to hybridization when manual cross-pollination is difficult and time consuming. However, the efficiency of this mutation might be investigated for breeding purposes because less than $50 \%$ of meiocytes were affected.

\section{ACKNOWLEDGMENTS}

Research supported by UNIPASTO (Brazil) and CNPq.

\section{REFERENCES}

Al Achkar W, Sabatier L and Dutrillaux B (1989). How are sticky chromosomes formed? Ann. Genet. 32: 10-15.

Albertsen MC and Phillips RL (1981). Developmental cytology of 13 genetic male sterile loci in maize. Can. J. Genet. Cytol. 23: 195-208.

Atanassova B (2000). Functional male sterility in tomato (Lycopersicon esculentum Mill.) and its application in hybrid seed production. Acta Physiol. Plant. 22: 221-225.

Baker B, Carpenter ATC, Esposito MS, Esposito R, et al. (1976). The genetic control of meiosis. Annu. Rev. Genet. 10: 53-134.

Beadle GW (1933). A gene for sticky chromosomes in Zea mays. Z. Indukt. Abstamm. Vererb. 63: 195-217.

Carapetian J and Rupert EA (1977). Meiotic irregularities caused by interacting sterility genes in cultivated safflower (Carthamus tinctorius). Can. J. Genet. Cytol. 19: 103-109.

Caryl AP, Jones GH and Franklin FC (2003). Dissecting plant meiosis using Arabidopsis thaliana mutants. J. Exp. Bot. 54: 25-38.

Dowd MA, Gaulden ME, Proctor BL and Seibert GB (1986). Formaldehyde-induced acentric chromosome fragments and chromosome stickiness in Chortophaga neuroblasts. Environ. Mutagen. 8: 401-411.

Gaulden ME (1987). Hypothesis: some mutagens directly alter specific chromosomal proteins (DNA topoisomerase II and peripheral proteins) to produce chromosome stickiness, which causes chromosome aberrations. Mutagenesis 2: 357-365.

Golubovskaya IN (1979). Genetic control of meiosis. Int. Rev. Cytol. 58: 247-290.

Horner HT and Palmer RG (1995). Mechanisms of genic male sterility. Crop Sci. 35: 1527-1535.

Jain A, Zadoo SN, Roy AK, Kaushal P, et al. (2003). Meiotic system and probable basic chromosome number of Panicum maximum Jacq. accessions. Cytologia 68: 7-13.

Jank L, Resende RMS, Valle CB, Resende MDV, et al. (2008). Melhoramento Genético de Panicum maximum. In: Melhoramento de Forrageiras Tropicais (Resende RMS, Valle CB and Jank L, eds.). Embrapa, Campo Grande, 55-87.

Johnsson H (1944). Meiotic aberrations and sterility in Alopecurus myosuroides Huds. Hereditas 30: 469-566.

Kaul MLH and Murthy TGK (1985). Mutant genes affecting higher plant meiosis. Theor. Appl. Genet. 70: 449-466.

Klásterská I, Natarajan AT and Ramel C (1976). An interpretation of the origin of subchromatid aberrations and chromosome stickiness as a category of chromatid aberrations. Hereditas 83: 153-162.

Koernicke M (1905). Uber die wirkung von Rontgen- und Radiumstrahlen auf pflanzliche Gewebe und Zellen. Dtsch. Bot. Ges. 23: 404-415.

Martini G and Bozzini A (1965). Analisi di un mutante "sticky" in dotto da radiazioni in frumento duro Cappelli. Genet. Agr. 19: 184-194.

Mehra RC and Rai KS (1970). Cytogenetic studies of meiotic abnormalities in Collinsia tinctoria. I. Chromosomal stickiness. Can. J. Genet. Cytol. 12: 560-569.

Pessim C, Pagliarini MS, Jank L, Kaneshima MAS, et al. (2010). Meiotic behavior in Panicum maximum Jacq. (Poaceae: Panicoideae: Paniceae): hybrids and their genitors. Acta Sci. Agron. 32: 417-422.

Rao MK, Devi KU and Arundhati A (1990a). Applications of genic male sterility in plant breeding. Plant Breed. 105: 1-25.

Rao PN, Ranganadham P and Nirmala A (1990b). Behaviour of a 'sticky-desynaptic' mutant in pearl millet. Genetica 81: 221-227. 
Savidan YH, Jank L, Costa JCG and Valle CB (1989). Breeding Panicum maximum in Brazil. 1. Genetic resources, modes of reproduction and breeding procedures. Euphytica 41: 107-112.

Shifriss C (1997). Male sterility in pepper (Capsicum annuum L.). Euphytica 93: 83-88.

Singh RJ (1993). Plant Cytogenetics. CRC Press, Boca Raton.

Sosnikhina SP, Kirillova GA, Mikhailova EI, Tikholiz OA, et al. (2003). Abnormal condensation of meiotic chromosomes caused by the mei8 mutation in rye Secale cereale L. Genetika 39: 362-369.

Sosnikhina SP, Mikhailova EI, Tikholiz OA, Priyatkina SN, et al. (2005). Genetic collection of meiotic mutants of rye (Secale cereale L.). Russ. J. Genet. 41: 1310-1321.

Tatum TC and Rayburn AL (2006). PRINS-labeled knobs are not associated with increased chromosomal stickiness in the maize st1 mutant. J. Hered. 97: 417-422.

Tsvetova MI and Elkonin LA (2003). Cytological investigation of male sterility in sorghum caused by a dominant mutation (Mstc) derived from tissue culture. Sex. Plant Reprod. 16: 43-49. 